\title{
Schlichtungsstellen
}

\section{BGH schafft Klarheit zur Verjährung in Arzthaftungsfällen}

\author{
Der Antrag eines Patienten bei einer Schlichtungsstelle der Ärztekam- \\ mer hemmt die Verjährungsfrist. Dazu ist es keineswegs nötig, dass der \\ betroffene Arzt oder seine Versicherung dem Schlichtungsverfahren \\ zugestimmt haben.
}

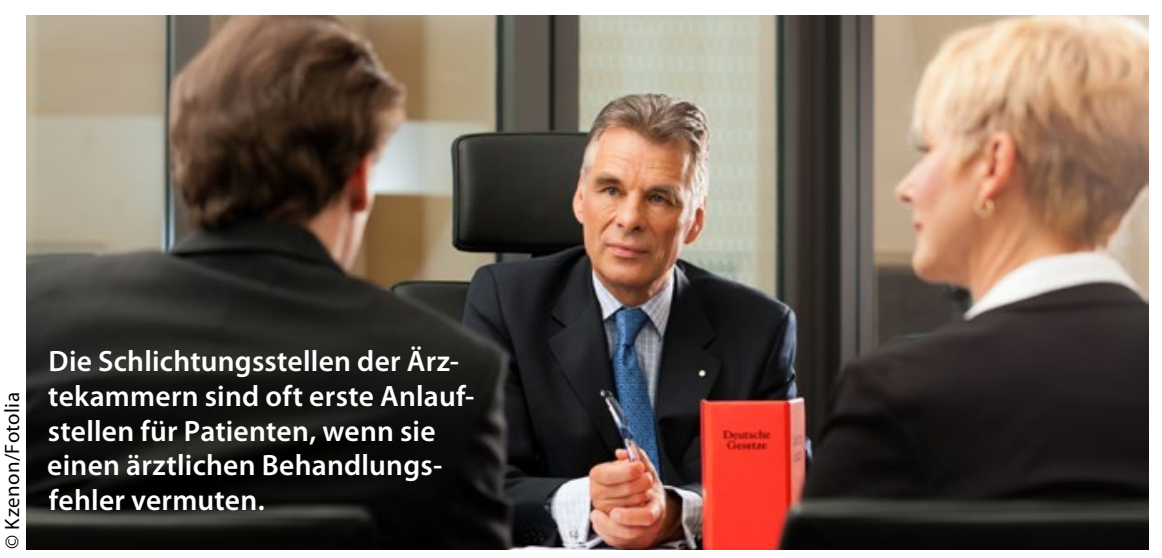

$\mathrm{R}$ ufen Patienten wegen einer angeblichen Fehlbehandlung durch einen Arzt die Schlichtungsstelle einer Ärztekammer an, wird die Verjährung zunächst gehemmt. Hierfür ist es nicht erforderlich, dass der Arzt oder seine Haftpflichtversicherung der Schlichtung zustimmen. Das befand kürzlich der Bundesgerichtshof (BGH; Az.: VI ZR 239/15).

Im entschiedenen Streitfall hatte ein Arzt eine Borreliose nicht erkannt. Die Infektion löste nachfolgend eine Arthritis in nahezu sämtlichen Gelenken des Patienten aus. Der Betroffene entschloss sich allerdings erst spät, Schadenersatz einzufordern. Entsprechende Ansprüche wären Ende 2011 verjährt. Kurz vorher, am 22. Dezember 2011, rief der Patient die Schlichtungsstelle der norddeutschen Ärztekammer an.

Im Februar 2012 akzeptierte dann der Mediziner die Schlichtung. Seine Versi- cherung stellte sich allerdings quer: Der Arzt habe der Schlichtung erst nach Eintritt der Verjährung zugestimmt; mögliche Ansprüche des Patienten seien daher verjährt.

\section{BGH hob Urteile der Vorinstanzen auf}

Das Landgericht Erfurt und das Oberlandesgericht Jena waren dieser Argumentation noch gefolgt. Die Geltendmachung von Ansprüchen bei einer nicht staatlichen Schlichtungsstelle hemme laut Gesetz die Verjährung nur, wenn das Verfahren „im Einvernehmen mit dem Antragsgegner betrieben wird“. Der BGH hob die Urteile der Vorinstanzen jedoch auf. Die Verjährung sei gehemmt gewesen, der Streit daher nicht verjährt.

Jetzt soll das Oberlandesgericht Jena die Schadenersatzforderungen inhaltlich prüfen. Zur Begründung verwiesen die Karlsruher Richter auf eine weitere Gesetzesvorschrift. Danach wird bei einer Verbraucherschlichtungsstelle oder einer „branchengebundenen anderen Gütestelle“ das Einvernehmen „unwiderleglich vermutet“.

Nach dem Karlsruher Urteil ist dies auch auf die Verjährungshemmung durch Anträge bei den Schlichtungsstellen der Ärztekammern anwendbar. Auf die Zustimmung durch den Arzt oder seine Versicherung komme es dabei gar nicht an. „Dies gilt auch dann, wenn ein Schlichtungsverfahren nach der Verfahrensordnung der jeweiligen Schlichtungsstelle nur dann durchgeführt wird, wenn Arzt und Haftpflichtversicherer der Durchführung des Verfahrens zustimmen", heißt es in der Urteilsbegründung. Scheitert die Schlichtung, haben Patienten für eine Klage weitere sechs Monate und zehn Tage Zeit. Bei der Fristbemessung zähle der Tag, an dem das Scheitern der Schlichtung mitgeteilt wird, noch nicht mit, betonte der BGH. In dem konkret entschiedenen Fall hatte die Schlichtungsstelle am 13. April 2012 über die Einstellung des Verfahrens informiert. Am 23. Oktober desselben Jahres - und damit gerade noch rechtzeitig - sei die Klage eingegangen.

Der Präsident der Ärztekammer Westfalen-Lippe Dr. Theodor Windhorst hat die jüngste Entscheidung des Bundesgerichtshofs zur Arzthaftpflicht begrüßt. „Diese Entscheidung ist ein Schritt in die richtige Richtung, um bei Behandlungsfehlervorwürfen den betroffenen Patienten nicht unter Zeitdruck zu setzen", sagte Windhorst. Der Arzt könne Vorwürfe nicht einfach aussitzen. Nach seiner Ansicht bieten die Schlichtungsstellen der Ärztekammern einen „Doppelschutz für Patienten und Ärzte“.

Martin Wortmann 